\title{
Endoscopic intraluminal cutting technique for indwelling devices using a lithotripter handle and guidewire
}
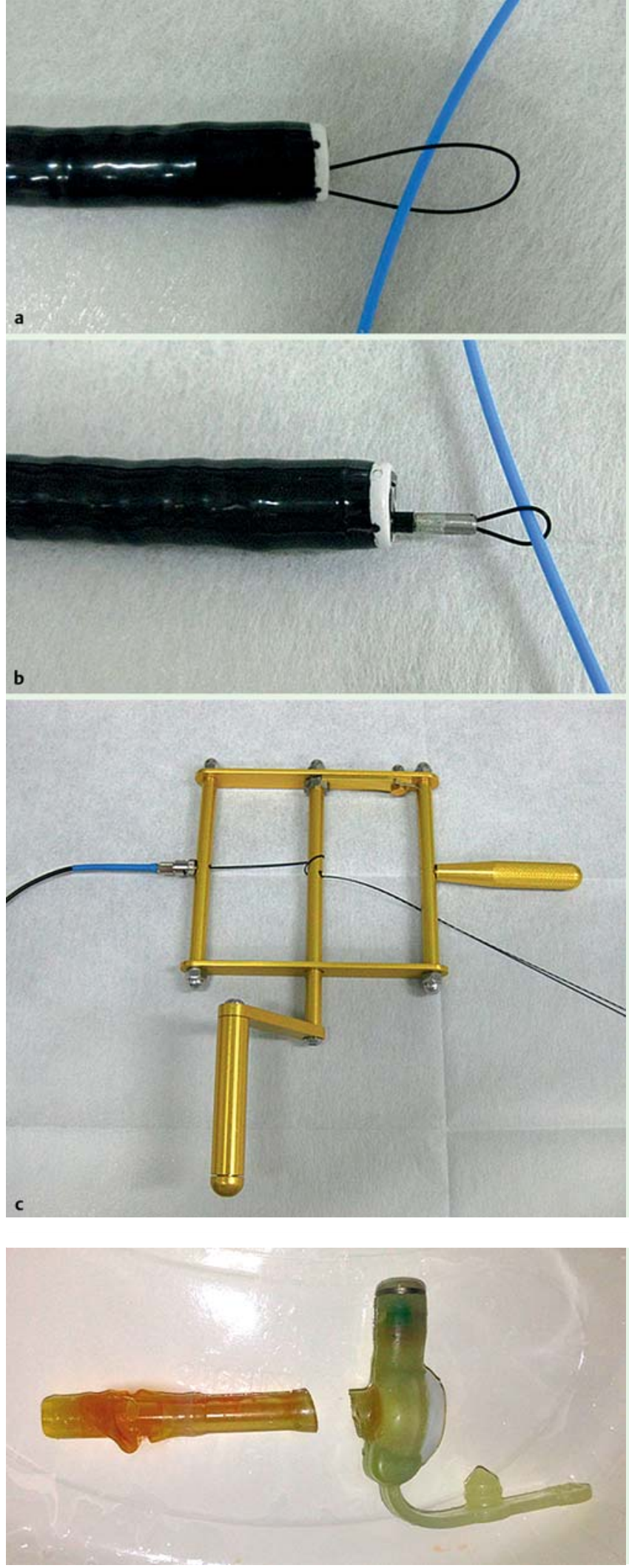

Fig. 1 Photographs showing: a a loop made with the guidewire around the "indwelling" device; b the lithotripter cable inserted over the guidewire; c the guidewire and the cable connected to the handle.

Fig.3 Photograph showing the two extracted pieces of the percutaneous endoscopic gastrostomy (PEG) tube after they had been cut using our technique.

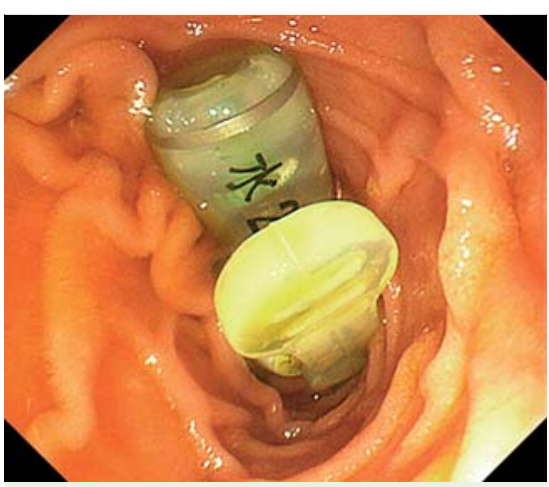

Fig. 2 Endoscopic view showing the percutaneous endoscopic gastrostomy (PEG) tube that had migrated into the duodenum.

Many transmural endoscopic devices have been developed for various different procedures; however, few options exist to endoscopically process these indwelling devices once they have been positioned. Here, we introduce a novel technique that allows indwelling devices to be cut endoscopically using a combination of an endoscopic retrograde cholangiopancreatography (ERCP) lithotripter handle and a guidewire, as illustrated in these two patients.

The procedure is performed as follows: (i) an ERCP guidewire (VisiGlide 0.025 inch; Olympus, Tokyo, Japan) is inserted through a therapeutic endoscope (GIF-1T240; Olympus) and is looped around the indwelling device using a biopsy forceps (FB-45Q-1; Olympus) ( $\bullet$ Fig. 1a); (ii) a lithotripter cable (Conquest TTCL-1; Cook Japan Inc., Tokyo, Japan) is inserted over the guidewire up to the indwelling device $(\bullet$ Fig. 1b); (iii) the guidewire and the cable are connected to the lithotripter handle (Soehendra; Cook Japan Inc.) $(\checkmark$ Fig. 1 c); (iv) the guidewire is reeled in using the handle, until the tightened loop of the guidewire cuts through the indwelling device $(\bullet$ Video 1$)$.

\section{Video 1}

A demonstration of the cutting procedure, which is performed by tightening the loop of the guidewire. 
The first patient was a 90-year-old woman who was admitted to our department because her percutaneous endoscopic gastrostomy (PEG) tube had migrated into her duodenum ( $\bullet$ Fig. 2). No conventional endoscopic devices were able to cut the PEG tube; however, using our technique, the tube was successfully cut into two pieces. Both pieces were then removed endoscopically without any complications ( Fig.3).

The second patient was a 60-year-old man who was referred to our department with postoperative pancreatic pseudocysts. After the pseudocysts had shrunk remarkably with effective endoscopic ultrasound (EUS)-guided drainage, the external drain was successfully converted into an internal drain by cutting the tube using our technique ( Video 2 ).

\section{Video 2}

An external drain is converted into an internal drain by cutting the drainage tube using our technique.
Our technique has some advantages over previously reported endoscopic scissor forceps $[1,2]$. Our method is highly capable of cutting hard materials because the lithotripter system used was originally designed to fracture large common bile duct stones. The technique can be easily and immediately introduced because all the required devices are commercially available.

Endoscopy_UCTN_Code_TTT_1AO_2AD

\section{Competing interests: None}

\section{Yu Muta', Yoshihiro Nishikawa',} Kotaro Watanabe ${ }^{2}$, Koichiro Kawano ${ }^{2}$, Hiroshi Seno ${ }^{1}$, Tsutomu Chiba ${ }^{1}$, Shujiro Yazumi ${ }^{2}$

${ }^{1}$ Department of Gastroenterology and Hepatology, Kyoto University Graduate School of Medicine, Kyoto, Japan

${ }^{2}$ Digestive Disease Center, The Tazuke Kofukai Medical Research Institute, Kitano Hospital, Osaka, Japan

\section{References}

1 Yang CW, Yen HH. Combined biopsy forceps and scissor forceps facilitate cutting the detachable loop entrapped in a large pedunculated polyp. Endoscopy 2012; 44: E202E203

2 Uchida N, Ezaki T, Fukuma $H$ et al. Conversion of endoscopic nasobiliary drainage to internal drainage by means of endoscopic scissor forceps. Endoscopy 2002; 34: 180

\section{Bibliography}

DOI http://dx.doi.org/

10.1055/s-0034-1391836

Endoscopy 2015; 47: E251-E252

(c) Georg Thieme Verlag KG

Stuttgart · New York

ISSN 0013-726X

\section{Corresponding author}

Shujiro Yazumi, MD, PhD

Digestive Disease Center

The Tazuke Kofukai Medical Research Institute Kitano Hospital

2-4-20 Ohgimach, Kita-ku

Osaka $530-8480$

Japan

Fax: +81-6-63610588

s-yazumi@kitano-hp.or.jp 